\title{
Anthós
}

$9-2015$

Delinquent Youth: The Ofuna New Wave

Basil Swartzfager

Portland State University

Follow this and additional works at: https://pdxscholar.library.pdx.edu/anthos

Part of the Other Film and Media Studies Commons, and the Visual Studies Commons Let us know how access to this document benefits you.

Recommended Citation

Swartzfager, Basil (2015) "Delinquent Youth: The Ofuna New Wave," Anthós: Vol. 7: Iss. 1, Article 8. https://doi.org/10.15760/anthos.2015.63

This open access Article is distributed under the terms of the Creative Commons Attribution-NonCommercialShareAlike 4.0 International License (CC BY-NC-SA 4.0). All documents in PDXScholar should meet accessibility standards. If we can make this document more accessible to you, contact our team. 


\section{Delinquent Youth: The Ofuna New Wave}

As in other booming post-war economies, such as the United States and Italy, the late1950s began a sea change in Japanese media consumerism. A new youth market had emerged full of excitable adolescents with money to burn and a hunger for entertainment. The popular success of the taiyozoku films, which targeted these young consumers by focusing on rebellious disenfranchised adolescents, inspired one of Japan's largest studios, Shochiku Co. Ltd., to break with its tradition of classical Japanese drama (best exemplified by the studio's two biggest directors, Yasujiro Ozu and Mikio Naruse) and attempt to capture some of this new capital. Thus, in 1960, studio head Shiro Kido promoted four promising young assistant directors to the rank of full director and, joining Nagisa Oshima who had been promoted the year before, these five became known as the Ofuna New Wave ("Ofuna" for the location of Shochiku studio headquarters). But was this media-christened New Wave a cohesive, intentionally-directed movement along the lines of Jean-Luc Godard and Francois Truffaut's work in the Nouvelle Vague (from which Ofuna was given its name), or was the moniker simply a useful marketing ploy to more easily package these new film products? In order to better understand 1960 as a landmark year in Japanese film, I will attempt to answer this question through close readings of three Ofuna films from that year which deal with this new taiyozoku phenomenon, and search them for thematic, stylistic, and narrative connections. The films to be analyzed are Nagisa Oshima's Cruel Story of Youth, Yoshishige Yoshida's Good-For-Nothing, and Masahiro Shinoda's Youth in Fury. Unfortunately the works of the other two Ofuna members, Osamu Takahashi and Tsutumo Tamura, are not available in English, so they will be omitted from this research. As a cross point to the Shochiku films this paper will compare those works to a 1960 film made at rival studio Nikkatsu, Koreyoshi Kurahara's The Warped Ones (considered part of 
the more broadly defined Japanese New Wave), in order to look for noted differences or similarities. Finally, 1950s films known to have directly inspired the Ofuna directors will be analyzed to further place the Ofuna directors in the appropriate film historical context.

Perhaps more than any other so-called New Wave filmmaking that occurred in this era, Japan's seems fundamentally rooted in the political climate that the films were made in. As such I will begin by attempting to elucidate some necessary context for these films, as detailed by David Desser in his book on the Japanese New Wave, Eros Plus Massacre. In the beginning of 1960 Japan's Prime Minister, Nobosuke Kishi, was to fly to Washington in order to sign the Treaty of Mutual Cooperation and Security between the United States and Japan. The treaty was first introduced in 1951, with the possibility of amendment every ten years. Fearing the continuation of one-sided Western influence from the United States as a result of the treaty (particularly, the stationing of multiple U.S. military bases throughout Japan) leftist students and labor unions gathered in huge numbers at the airport to block the prime minister's flight. This initial protest failed, and the treaty was signed on January 19th. Undeterred, enormous groups began protesting in front of the Diet building (Japan's parliament) in the hopes of swaying the Diet into overturning the prime minister's decision. Thousands of student protesters marched with picket signs around the Diet building, culminating in the largest mass protest in Japan's history. This demonstration ended in violence, as four thousand students stormed into the Diet complex the night of June 15th, 1960, and were violently ejected in a clash with Tokyo police. Hundreds were injured and one young woman protester was killed during this escalation (Desser 35). Two of the three Shochiku films to be analyzed in this paper involve the Diet protests, and Nagisa Oshima's later 1960 film, Night and Fog in Japan, bases its narrative as a direct response to the failure of these demonstrations. By coincidence or by design the two most significant 
Nikkatsu taiyozoku films from the same year, Seijun Suzuki's Everything Goes Wrong and Koreyoshi Kurahara's The Warped Ones, do not mention the protests at all. While this evidence is mostly circumstantial, it does point to an overlapping political interest among the Shochiku filmmakers that is absent from their contemporaries working in the same genre.

Before delving fully into the triad of analysis that will make up this paper's main body, I would like to further illuminate the context of the taiyozoku phenomenon, and its origins. The phrase "taiyozoku" was coined by novelist Shintaro Ishihara in his 1955 book, Season of the Sun (turned into a film in 1956), and refers to a new breed of Japanese adolescent obsessed with Hawaiian shirts, beach life, American jazz music, and nihilism. The enormous success of Season of the Sun led to a flood of taiyozoku-focused films at Nikkatsu, and gave the Shochiku new wave directors their seminal inspiration, Ko Nakahira's Crazed Fruit. In his 1958 essay for Film Review, "Is It a Breakthrough? (The Modernists of Japanese Film)" Nagisa Oshima champions Crazed Fruit, stating "in the rip of a woman's skirt and the buzz of a motorboat, sensitive people heard the heralding of a new generation of Japanese film" (Oshima 26). Oshima finds in Nakahira's film -- along with Yasuzo Masumura's 1957 debut, Kisses -- a strength of selfperception and rebellion against the traditional forms of Japanese cinema that would inform his later directorial intentions (Oshima 29). The debt owed to Nakahira's film, both stylistically and thematically, by the Ofuna directors already begins to bring doubt to the entire notion of an Ofuna New Wave. Nagisa Oshima is historically considered the father of this New Wave movement and, as such, it often is said to begin with either his first feature film, A Town of Love and Hope in 1959, or his breakout international success in early 1960, Cruel Story of Youth. But why does the movement start there? As Oshima himself has pointed out, both Nakahira and Masumura break from the traditional model of Japanese filmmaking that the Ofuna New Wave 
was heralded as being a reaction to. In one of Crazed Fruit's pivotal scenes Nakahira uses a series jutting, angular close-ups to frame these taiyozoku youths as they deliver a monotone epitaph to Japan's education system. School is pointless, they claim, because their professors teach classes as if the last twenty years of Japanese history has not occurred. The shame of defeat in World War II, and the decade of intense militarist fascism leading up to the war, have caused a cultural amnesia that these disillusioned youths find repugnant. The pessimism of this scene, along with its intensely skeptical attitude towards the authority of the previous generation, would be echoed in the Ofuna New Wave films. Its stylistic content is equally aggressive, as these rapid, sharp close-ups (which alternate traditional straight-on shots with disorienting high angles looking down the planes of foreheads and noses) mark a violent contrast to the relatively benign close-ups of Ozu and Kurosawa. In some ways Nakahira pushes this stylistic envelope even further than his Ofuna descendants (save, perhaps, Oshima himself). In a later night club scene Nakahira combines film noir style low key lighting to create dynamic shadows with a hazy wide angle lens that distorts a zoot suit wearing teen as he tries to coerce a woman to dance with him. Shot from her point of view, the camera transforms the hand he extends into a blurred nightmare, an enormous threatening presence that dominates the bottom of the frame. Masumura's Kisses, while far more optimistic than Crazed Fruit or any of the Ofuna films, still represents an enormous shift in Japanese film style. In order to place itself in direct competition with the burgeoning television comedy market, Masumura's film creates an energetic, non-stop pace of banter between the male and female lead in a style reminiscent of Howard Hawks' His Girl Friday. This motor-mouthed frenzy of speech shocked audiences accustomed to a more contemplative mode of dialogue which, even in the heights of anger, rarely sustained rapidity for more than a minute (Rosenbaum, "Masumura's Madness"). Kisses represents 74 minutes of 
frenetic exuberant energy. Despite its relative optimism, the film is not without its own sense of political conscience. The meet-cute that introduces the male and female characters occurs at a prison, where each adolescent is visiting their respective incarcerated father -- the boy's for repeated election fraud, the girl's for embezzlement of company funds. This awareness of institutional corruption, and an ending that shows the boy's transition into manhood by abandoning his unrepentant father to prison life, easily combine with the film's formal innovations to give it the same hallmarks afforded the later, "official" New Wave films.

So what, if anything, distinguishes the young Shochiku filmmakers from a Nakahira or a Masumura other than their unification under a single company, and the new availability of a ready-made moniker? Can the Ofuna New Wave be analyzed as representing a significant step forward from these early precursors? While it does not provide a complete, or concrete, answer, we can turn to Oshima's subtle critique of these two films in order to discover where he believes the difference lies. In the same article ("Is It a Breakthrough?...") Oshima praises these two films for their directness, their trueness to the internal authorial spirit of critique, and their unique point of view. Oshima also points to a quality of the films that, if not addressed, could undo the valuable work these directors have begun to contribute. "The modernists," he says, "are at a crossroads. One road would lead to gradual degeneration of their innovations in form into mere entertainment, bringing about their surrender to the premodern elements that are subconsciously included in the content of their films" (33). These "premodern elements" are, for Oshima, a cultural bond to the older traditions of Japan that can prove inescapable, and must be constantly warred against. Later in the essay he quotes Jean-Paul Sartre, "what we want is for artists to solidly embrace their own era" (35). In this way Oshima is calling for stronger attention to the present, to the given circumstances of Japan in this historical moment, and a righteously 
expressed critique of one's socio-political landscape through the artist's unique point of view. In examining Cruel Story of Youth, it would seem that he succeeded in this goal. Stylistically he moves away from the beautiful, if mostly traditional, formal compositions he displayed in $A$ Town of Love and Hope towards a more off-putting, intentionally off-kilter compositional design. The transition is noticeable from the film's first scene, in which the heroine, Makoto, and a friend hitch a ride home from an older man. When the two women climb into the car, the camera intentionally disregards traditional film language for driving scenes and shoots the entire scene from the rear window of the car, mostly leaving the viewer to stare at the backs of the actors' heads. The very next scene continues this odd staging, as the man tries to physically assault Makoto outside a hotel after she refuses to go in with him and is rescued by the film's male lead, Kiyoshi. Kiyoshi attacks the man, who fights back, and the entire fight is filmed in a single take that is, at best, a very close medium shot. Rather than pull back to assist the viewer in understanding the body positions of the combatants, Oshima keeps the camera tight and even allows the actors to move in and out of frame, heightening the disorientation of the fight. It only lasts a few seconds, but again demonstrates Oshima's stylistic dedication to breaking convention. This interest in the camera as its own entity, with an agency that grafts the audience to the action, comes forward in another notable scene. Later in the film Makoto tries to break up with Kiyoshi, and he coerces her to stay with him. The scene, much longer than the fight, is again filmed in a single take that maintains an uncomfortable closeness to the actors. Through the use of Cinemascope, Oshima is able to frame both Makoto and Kiyoshi in close-up in the same frame. Each time she offers her reasoning for wanting to leave, she retreats a few steps away from Kiyoshi (and, thus, the camera). Kiyoshi counters with his own reasons why she shouldn't leave, and as he strides to catch up to her the camera follows him. They pause and argue, the camera's 
placement momentarily docile, and the process begins again. Though Kiyoshi is never presented as a likable character, the film in this moment aligns the audience with Kiyoshi. We become predators chasing Makoto, forcing her to stay -- because if we didn't, the movie would be over. In this way Oshima implicates the audience in the tragic perversion of Kiyoshi and Makoto's adolescence, asking the people watching the film to consider their own part in propagating a society that allows these youths such a horrible conclusion.

Narratively, Cruel Story of Youth shares much in common with Shinoda's Youth in Fury and Yoshida's Good-For-Nothing. All three concern themselves with disenfranchised students, and Oshima's and Shinoda's films, both filmed during the Diet protests, make active use of actual protesters in location scenes, along with narrative reference points. In Oshima's film, Kiyoshi plays a college student who frequently skips class and, like the taiyozoku of Crazed Fruit, remains nihilistically indifferent to studying. But, as a counterpoint to Kiyoshi, Oshima positions a young activist student friend, who is seen near the beginning of the film marching in the Diet protests. But even though the protests had not finished by the time the film was completed, it seems Oshima was already (correctly) convinced of their failure. As David Desser points out, an older former student activist -- and now an abortionist -- Dr. Akimoto, admits his regret that he was not able to enact any social change in the '50s, and thus, the audience infers, feels a sense of responsibility for the way Kiyoshi and Makoto have turned out. Kiyoshi replies, "We have no dreams, so we'll never be like you" (49). This again reveals a deep-rooted, inescapable pessimism that harkens back to Nakahira's Crazed Fruit. However this pessimism also, if one investigates Oshima's personal biography, reveals a sense of self-loathing. Oshima, like Akimoto, was a student activist in the early 1950s at the prestigious Kyoto University, and became quite infamous after a huge demonstration of students picketed the visiting Emperor, 
urging him to be wary of claiming a deified status and following in the footsteps of Hirohito (Turim 8). This sense of inner disgust and outward fury at the inability of the Communist student party to affect change in the ' 50 s is addressed even more explicitly in Oshima's later film, Night and Fog in Japan.

Masahiro Shinoda's second film for Shochiku, Youth in Fury, was fortunate to have been written after the Diet protests started but finished production before they concluded. Speedy turnaround was a hallmark of Japanese studios at this time, having modeled themselves after the vertically integrated Hollywood studios of the '20s-' 40 s, and this level of immediate social commentary could rarely have been achieved before or after. If the ultimate goal of any artist can be deduced by the aforementioned quote from Jean-Paul Sartre, then Masahiro Shinoda succeeded in perhaps the most direct way of any Ofuna filmmaker, embracing his own era to the extent of making a fictional film about a historical event as it is occurring. The film's narrative concerns three students at a university, and their varying participation in student politics and the Diet protests in particular. Audie Bock quotes Shinoda in her book Japanese Film Directors stating that he would "like to be able to take hold of the past and make it stand still so that [he] can examine it from different angles" (341). Applying this ideal to the narrative structure of Youth in Fury reveals its more multi-faceted intentions, when compared to the closed systems of Cruel Story of Youth and Good-For-Nothing. Each of the three characters in Youth in Fury exists with its own story arc that is only intermittently connected to the other two. As Desser has pointed out, these three characters represent what Shinoda and screenwriter Shuji Terayama see as the three factions of Japanese youth culture. Shimojo, with his black leather jacket and worship of jazz, represents the apotheosis of taiyozoku culture -- a form of nihilism so complete and self-serving that it ends in a return to the fascism of Hitler. On the other end, though equally 
despicable, is Michihiko, a student from an extremely wealthy family. He represents the burgeoning capitalists of Japan, whose obsession with profit and decadent displays of monetary gain eradicate human compassion. Yoko, the female protagonist, represents the middle of this spectrum, and the only point of hope seen by Shinoda (Desser 37). Compared to the heroes in Oshima's and Yoshida's work, Yoko represents a relative high point in terms of Ofuna New Wave optimism. Throughout the film she manages to maintain her own sense of agency, never submitting to the systems that, for Oshima and Yoshida's characters, are inescapable. In the film's end she joins the Diet protests and, unlike their depictions elsewhere, the film contains a sense of hopefulness in her activism.

If Youth in Fury seems less radical politically than Oshima's explosive pessimism, it retains this detached moderation in its style as well. Despite being filmed after Cruel Story of Youth had been released, and despite carrying some of the same New Wave calling cards (handheld cameras, on-location shooting), the film otherwise seems to lack a departure from the traditional Japanese classical cinema style. A self-professed lover of Ozu, whom he worked under as an assistant, Shinoda mostly carries that director's penchant for closed interiors and medium to medium-long shots, albeit without Ozu's meticulous attention to blocking and space. A few of the exterior scenes, in which characters walk and talk, are shot from the side in a jittery handheld style somewhat similar to the one Oshima employs. But less sense is given that this strategy is intended as an aggressive political stance, or a function of implicating the audience within the psychology of the characters, the way Oshima's work does. Instead the film's style could be described as utilitarian. The film was made quickly, and seems to employ strategies that make the most sense in order to put the script to film in the most efficient and simplest way possible. 
Yoshishige Yoshida's Good-For-Nothing is less overtly concerned with politics, and its story of delinquent youths focuses on class stratification rather than direct political upheaval. The film's plot concerns a group of taiyozoku students of various income levels, one rich, Akiyama, and two poor, Toshio and Jun. The distinction made between the two poor students comes from the comfortability with which they leech off of Akiyama's wealth. Toshio comes to represent a lower-class version of the Michihiko character displayed in Youth in Fury, one whose humanity is destroyed by his obsession with money as a synonym for power. Toshio is initially portrayed more sympathetically than Michihiko, as he confronts Akiyama for his disaffected nihilism in an early scene. Akiyama claims that money has made his life too easy, too boring, and he can no longer feel passionate about anything he sees. Toshio scoffs at his privilege and rightfully points out that only a rich person could romanticize being poor in such a ridiculous way. But as the film progresses Jun becomes the clear protagonist, torn between a spiral of socially inflicted self-loathing regarding his low-income status and the possibility of redemption offered by a woman who sees good in him. In the end Jun cannot accept the compassion she offers him, and he retreats to the ruthless veneer of the taiyozoku that he feels society expects of him. As one might expect, this ends in tragedy when Toshio and Jun participate in a robbery that goes badly, and Jun ends the film running down the street shot in the gut, in a direct homage to Jean-Luc Godard's Breathless. While Godard's film encourages the audience's indifference to Michel's death, Yoshida's use of the same tactic seems designed to instill sympathy for the tragic figure. In this way it moves towards a more conventional melodrama along the lines of classical Japanese cinema, and away from the more revolutionary tensions Oshima suggests are necessary for the future of Japanese cinema.

The only of the three to film in black and white, Good-For-Nothing feels stylistically 
even more conventional and restrained than Shinoda's. Most of the film's tracking shots, save the aforementioned finale, seem as though they are done smoothly on a dolly or from a moving car, rather than being carried by a human. The lighting scheme recalls Crazed Fruit in its intense shadows and play with light and dark, but it never reaches the sometimes dreamlike expressiveness of that film.

Compared to Yoshida and Shinoda's films Koreyoshi Kurahara's The Warped Ones, a 1960 Nikkatsu film about the taiyozoku,, feels like an explosion of attitude and style. Borrowing liberally from Godard's use of rapid montage, jump cuts, and disorienting car travel, while ignoring Godard's tendency to slow down and let certain scenes linger, Kuraraha uses the construction of the film to intentionally mimic the insatiable psychology of its main character. As a result The Warped Ones becomes a relentlessly stylized and paced film that crafts a narrative of a recently released juvenile delinquent named Akira stalking his way through an unsuspecting, but surprisingly permissive Tokyo. In nearly every scene he breaks some sort of crime or social convention, and all he receives is mild admonishment. Without mentioning the failure of the Diet protests specifically, the film still echoes that protest's fear of cultural erasure, as the jazz-obsessed Akira proclaims of Japan "what a shitty country" and later declares Japanese people "the worst." But, unlike Shimojo in Youth in Fury, Akira does not deify American aesthetics. Throughout the film the white American man is portrayed as a foolish mark to be taken advantage of, and the film's first scene shows Akira's female friend, a prostitute who specializes in American G.I.s, soliciting a slack-jawed officer and then running off with his money. In this world of exploitative Americans and subservient, hypocritical Japanese, Akira reverts to a simian id, spending the entirety of the film doing exactly what he wants at any given moment. He is unbound by social constraints, and no one in Tokyo seems capable of stopping 
him. Heavily inspired by early modernist painting, especially the Italian futurists' ideas of speed and violence, The Warped Ones feels much closer to the ideal of personal expression and tension with reality that Oshima claims is required of a strong Japanese director than either Yoshida or Shinoda end up with.

As early as 1960 Oshima opposed the journalistic dubbing of the "Ofuna New Wave." As Audie Bock states, "He maintained that there were too few 'new directors' to constitute a 'wave,' and moreover that they were all working within the restrictions of the company system, which hampered the emergence of a true avant-garde" (317). Oshima would later even claim that the fact that Yoshida, Shinoda, and he had chosen the taiyozoku genre for their 1960 films was a coincidence, though this claim is rather suspect given their close working relationships and known film theory discussions around the same time (Desser 47). But a close analysis of these early films by Yoshida and Shinoda reveals that the revolutionary nature of their work, relative to what was going on outside Shochiku at the same time, has been historically overstated. Yoshida and Shinoda are mostly well-known for later work in the '60s and early '70s, and it is possible that this work is characterized by the traits film history now associates with the Japanese New Wave. The Ofuna New Wave, however, ended in 1961 after two incidents shifted the enthusiasm away from Shochiku's new stable. The first occurred when Oshima, furious at the studio's pulling of Night and Fog in Japan from theatrical distribution, quit the company to form his own independent production studio. The second occurred when Shochiku, disappointed in the sales results of these Ofuna New Wave films, cancelled the project, returning Shinoda briefly to the role of assistant-director and causing Yoshida to follow in Oshima's footsteps and leave the studio. So while it is possible to view these early films as precursors to those directors' later New Wave works, the importance of the Ofuna New Wave as a movement towards a revolution 
in Japanese cinema has been overstated. An alternative history could easily posit Ko Nakahira as the father of the Japanese New Wave, with Yasuzo Masumura, Seijun Suzuki, Koreyoshi Kurahara and Nagisa Oshima following in his wake, which would more accurately trumpet the modernist successes of directors across all studios without overly celebrating the relatively modest work done by those who happened to work at the same studio as Oshima. 


\section{Works Cited}

Bock, Audie. Japanese Film Directors. New York: Kodansha International, 1978. Print.

Desser, David. Eros Plus Massacre: An Introduction to the Japanese New Wave Cinema. Bloomington: Indiana University Press, 1988. Print.

Kurahara, Koreyoshi, dir. The Warped Ones. Criterion, 1960. Hulu. Web. 20 Feb. 2014.

Masamura, Yasuzo, dir. Kisses. Daiei Studios, 1957. Karagara.net. Web. 20 Feb. 2014.

Nakahira, Kō, dir. Crazed Fruit. Criterion, 1956. Hulu. Web. 20 Feb. 2014.

Oshima, Nagisa. Cinema, Censorship, and the State: The Writings of Nagisa Oshima, 1956-1978. Ed. Annette Michelson. Trans. Dawn Lawson. Cambridge: MIT Press, 1992. Print.

Oshima, Nagisa, dir. Cruel Story of Our Youth. Criterion, 1960. Hulu. Web. 20 Feb. 2014.

---. Night and Fog in Japan. Criterion, 1960. Hulu. Web. 7 Feb. 2014.

---. A Town of Love and Hope. Shochiku Eiga, 1959. Karagarga.net. Web. 20 Feb. 2014.

Richie, Donald. A Hundred Years of Japanese Film: A Concise History, with a Selective Guide to Videos and DVDs. New York: Kodansha America, 2001. Print.

Rosenbaum, Jonathan. "Masumura's Madness + Sidebar.” Jonathan Rosenbaum.net. Jonathan Rosenbaum, 5 Sept. 2002. Web. 20 Feb. 2014. Rpt. of "Enlightened Madness." Film Comment 38.5 (2002): 32.

Shinoda, Masahiro, dir. Youth in Fury. Criterion, 1960. Hulu. Web. 20 Feb. 2014.

Turim, Maureen Cheryn. The Films of Oshima Nagisa: Images of a Japanese Iconoclast. Berkeley: University of California Press, 1998. PDF E-book.

Yoshishige, Yoshida, dir. Good-For-Nothing. Shochiku Ofuna, 1960. Karagarga.net. Web. 20 Feb. 2014 